\title{
Evaluation of cloud seeding project in Yazd Province of Iran using historical regression method (case study: Yazd 1 cloud seeding project, 1999)
}

\author{
Mojtaba Zoljoodi ${ }^{*}$, Ali Didevarasl ${ }^{\#, \dagger}$ \\ Atmospheric Sciences and Meteorological Research Center (ASMERC), Tehran, Iran; \\ †Corresponding Author: ali_didehvar714@yahoo.com
}

Received 9 June 2013; revised 9 July 2013; accepted 16 July 2013

Copyright (C) 2013 Mojtaba Zoljoodi, Ali Didevarasl. This is an open access article distributed under the Creative Commons Attribution License, which permits unrestricted use, distribution, and reproduction in any medium, provided the original work is properly cited.

\begin{abstract}
In this research, the result of the cloud seeding over Yazd province during three months of February, March and April in 1999 has been evaluated using the historical regression method. Hereupon, the rain-gages in Yazd province as the target stations and the rain-gages of the neighboring provinces as the control stations have been selected. The rainfall averages for the three aforementioned months through 25 years (1973-1997) in all control and target stations have been calculated. In the next step, the correlations between the rainfalls of control and target stations have been estimated about $75 \%$, which indicates a good consistency in order to use the historical regression. Then, through the obtained liner correlation equation between the control and target stations the precipitation amount for February, March and April in 1999, over the target region (Yazd province) was estimated about $27.57 \mathrm{~mm}$, whiles the observed amount was $\mathbf{3 4 . 2 3}$ $\mathrm{mm}$. In fact the precipitation increasing around $19.5 \%$ over Yazd province confirmed the success of this cloud seeding project.
\end{abstract}

Keywords: Cloud Seeding Project; Target and Control Stations; Historical Regression Method; Yazd Province

\section{INTRODUCTION}

Water is one of the most basic commodities on earth sustaining human life. In many regions of the world, how-

*Associate professor and chairman of ASMERC.

\#Senior expert of ASMERC. ever, traditional sources and supplies of ground water, rivers and reservoirs, are either inadequate or under threat from ever-increasing demands on water from changes in land use and growing populations. In many countries, water supplies frequently come under stress from droughts and increase pollution in rivers, resulting in shortages and an increase in the cost of potable water. Ground water tables have been steadily decreasing in many areas around the world where ground water is one of the primary sources of freshwater [1]. This is particularly evident in most parts of Iran. To help alleviate some of these stresses, cloud seeding for precipitation enhancement has been used as a tool to help mitigate dwindling water resources.

The first usually considered question after a cloud seeding operation is that "how much was the effect of this operation in rainfall increasing?" impact assessments of the cloud seeding were regarded from the initial seeding operations all around the world. The results derived through seeding of the stratus clouds that usually don't result in rainfall, are controllable by in situ observations or by using the radar based watch [2]. Whiles the impacts of convective cloud seeding, especially in the case of natural rainfall, often are hidden. Only a small part of the available moisture in clouds is transformed into precipitation that reaches the surface [3-6]. This fact has prompted scientists and engineers to explore the possibility of augmenting water supplies by means of cloud seeding.

The ability to influence and modify cloud microstructure in certain simple cloud systems such as fog, thin layer clouds, simple orographic clouds, and small cumulus clouds, has been demonstrated and verified in laboratory, modeling, and observational studies [7].

Australia has a long history of cloud seeding research and operations, with initial investigations occurring about 60 years ago. Between 1955 and 1959, the Snowy Mountains were the focus of an aircraft-based cloud seeding 
experiment run jointly by the Commonwealth Scientific and Industrial Research Organization (CSIRO) and the Snowy Mountains Hydro-Electricity Authority (SMHEA). From this experiment, Smith et al. (1963) reported a 19\% precipitation increase in seeded events; however, despite these encouraging results cloud seeding over the Snowy Mountains was not pursued [8].

A feasibility study by Shaw and King (1986) assessed the potential for cloud seeding over the Snowy Mountains as positive [9]. This study considered meteorologycal and cloud physics data over the region as well as the ecological, community and wider-area effects of cloud seeding. Further evaluation of the physical and chemical characteristics of the clouds and snowfall over the region during the winters of 1988-1989 [10] supported the findings of Shaw and King (1986) [9].

In 1993, SMHEA drafted an Environmental Impact Statement (EIS) proposing a six-year cloud seeding experiment over a $2000 \mathrm{~km}^{2}$ area of the Snowy Mountains [11]. This experiment did not proceed because of objecttions from key stakeholders. An independent expert panel report, addressing the principal objections that had been raised in 1993, was submitted to the New South Wales (NSW) government in 2003. The Snowy Mountains Cloud Seeding Trial Act (NSW) was passed in 2004 allowing Snowy Hydro Limited (SHL) to undertake a six year winter cloud seeding trial- the Snowy Precipitation Enhancement Research Project (SPERP). The objectives of SPERP are to determine the technical, economic and environmental feasibility of precipitation enhancement over the main range of the Snowy Mountains. In the scientific community weather modification is still viewed as a somewhat controversial topic. Changnon and Lambright (1990) identified several problems and difficulties that have arisen during the conduct of weather modification experiments [12]. According to Changnon and Lambright, based on their analyses of the National Hail Research Experiment and the Sierra Cooperative Pilot Program (SCPP), the major scientific controversies were a result of six factors. These factors were 1) proceeding with an inadequate scientific knowledge base; 2) a flawed project-planning process; 3) differing views between funding agencies and project scientists; 4) lack of continuing commitment by the principal agency conducting the experiment; 5) changes in project directors; and 6) poor performance by project scientists. Because of the complex nature of precipitation enhancement experiments, it is extremely important to funding agencies, water managers, and scientists that current experiments are critically reviewed in terms of these six factors in order to avoid repeating the mistakes listed above.

The results derived from two cloud seeding experiences over Israel have been presented by Nirel and Rosenfeld, 1996 and $1995[13,14]$. They evaluated the results of cloud seeding operation by using logarithmic models during these two periods 1961-1967 and 1970-1975, and then confirmed a precipitation increase around $13 \%$ to $15 \%$ in the target region.

In Iran, some studies have already been developed on evaluation of cloud seeding operations. Regarding the reports of the "Iran National Research Centre of Cloud Seeding Studies" in Yazd province, the cloud seeding project in 2008-2009 over Zagros mountain chain resulted in an increase of precipitation about $18.9 \%$. Meantime the results of cloud seeding over 2008-2009 in central plain of Iran indicated $19.5 \%$ of precipitation increase.

Through an impact assessment study on cloud seeding operation over Gavekhoni Watershed (in central Iran) in Feb 2010, using historical regression method, an increase of precipitation about $46.4 \%$ has been estimated [15]. Khalili et al. (2009) took under consideration the results derived through cloud seeding operations in Iran during 1999-2007 [16]. Based on their analyzes, the cloud seeding operations over central parts of Iran caused increase of seasonal precipitation around $22 \%-40 \%$.

\section{MATERIALS AND METHODS}

To estimate the effect of seeding it is necessary to estimate the long-range average of seeded precipitation in the contracted target, a sample of which is directly available, and also the similar long-range average of what would have fallen without seeding, for which no direct data exist. Thus, this latter estimation must be indirect and involves two arbitrary choices. One is the choice of the so-called "historical period" when there was no seeding. The other is the arbitrary choice of the so-called "control" area. The reader will notice that the precise meaning of "target" and "control area" is two sets of rain gauges functioning in the two localities. When these two choices are made, the observed historical precipitation amounts, averaged over gauges in the target and in the control areas, are used to estimate the linear regression equation of the historical target precipitation on that in the control. Next, this historical regression line and the operational period's precipitation in the control are used to estimate the mean precipitation in target to be expected without seeding.

In this work we have applied the historical regression method to find the success or un-success of the cloud seeding over Yazd province in 1999. The historical regression, is recounted the most usual applicable method to assess the cloud seeding results. This method is based on principal factors which would be affected by cloud seeding (such as: precipitation or snow). Data series of the principal factors through a long term (for example 25 years) should be analyzed.

For data gathering in this regard we chose two groups of rain gages as target and control stations. The control 
stations should be selected from the regions as fare as possible out of cloud seeding operation region/target region, but whiles should be representative of the same climate of the target region.

Historical data series of precipitation in both target and control regions are over a period before seeding operation. These two data series (which of target and control regions) have been analyzed to obtain a regression relationship between them to estimate the precipitation amount in the target region over the period of seeding operation without taking in account the seeding affect. Then the estimated precipitation, observed and the long term average are compared to find the amount of precipitation increase in target region. The equation below shows the regression relationship:

$$
\mathrm{Yt}=\mathrm{aYc}+\mathrm{b}
$$

Yt: estimated precipitation of target region

Yc: actual precipitation of control region

The coefficients of (a) and (b) are determined using historical precipitation data series before seeding operation through quantification of square error method.

Using of this method is recommended as there is a well correlation between the long term data series of the target and control regions. Climate similarity of target and control regions will result in a high correlation. For evaluating of precipitation, correlation coefficient (r) equal to $>0.9$ is appropriate. This research aims to study the derived results from cloud seeding project at 30 Jan to 29 Apr 1999 over Yazd province.

\section{POSITION OF THE STUDY AREA, AND SELECTION OF TARGET AND CONTROL STATIONS}

In this research, we used the data series of meteorological stations and rain gages over Yazd province through 1973-1997. Table 1 shows the position and founding time of these stations. We selected in total 19 stations and rain gages over our target region (Yazd province).

Among these selected 19 stations, Dihook and Saghand stations are ignored because of the limitation in statistical period that is less than 15 years. Thus 17 stations over Yazd province (an area about $125,000 \mathrm{~km}^{2}$ ) as the target stations for this project are taken in account. Yazd province placed in the central Iran is widely rough, as the elevations vary between $1000 \mathrm{~m}$ to $4000 \mathrm{~m}$ throughout this region. Spatial variation of precipitation over Yazd province is very high, as in the central regions the annual rainfall amount ranges $50 \mathrm{~mm}$ to $60 \mathrm{~mm}$, whiles, the western and southwestern regions of this province receive annual rainfall between $300 \mathrm{~mm}$ to $400 \mathrm{~mm}$. Rainfall period in this region usually lasts 8 months, from Oct to May, however $90 \%$ and $67 \%$ of it's total precipitation respectively events during Dec to May, and Jan to Apr

\section{(Figure 1).}

The control stations selected should have maximum climate similarity with the target region, as having a high correlation between their precipitations is necessary (Figure 2). In the Table 2 you can see the information of the 13 selected control stations. The geographic position of all selected target and control stations on the study area are illustrated through Figure 3.

Table 1. Selected target stations in Yazd Province.

\begin{tabular}{ccccc}
\hline Ltations & Lat & Lon & Elevation & Founding time \\
\hline Mohamad abad & 31.47 & 54.25 & 1250 & 1971 \\
Yazd & 31.54 & 54.17 & 1236 & 1952 \\
tabass & 33.3 & 54.55 & 791 & 1960 \\
Dihook & 33.17 & 57.31 & 1100 & 1962 \\
Abarkooh & 31.00 & 53.17 & 1500 & 1964 \\
Ardekan & 32.19 & 54.01 & 1400 & 1966 \\
Baigan & 31.37 & 55.5 & 1400 & 1966 \\
Ghatroom & 31.23 & 55.4 & 1500 & 1966 \\
Hajiabad zarrin & 33.09 & 54.51 & 1100 & 1966 \\
Kharanegh & 32.20 & 54.40 & 1000 & 1966 \\
Khoidak & 31.3 & 54.3 & 1300 & 1966 \\
Robat posht badam & 33.02 & 55.10 & 1200 & 1966 \\
Saghand & 32.33 & 55.11 & 1350 & 1966 \\
Taft & 31.45 & 54.14 & 1590 & 1966 \\
Hajiabad kariz & 31.20 & 54.00 & 2000 & 1967 \\
Dehshir & 31.20 & 53.44 & 1900 & 1967 \\
Hosseinabad rastagh & 32.14 & 54.12 & 1050 & 1967 \\
Mazraeh noo & 32.24 & 53.29 & 1350 & 1967 \\
Nasrabad pishkooh & 31.47 & 53.52 & 2050 & 1967 \\
\hline & & & & \\
\hline & & &
\end{tabular}

Table 2. Selected control stations in the neighboring provinces.

\begin{tabular}{ccccc}
\hline Stations & Lat & Lon & Elevation & Founding time \\
\hline Varzaneh & 32.26 & 52.39 & 1470 & 1968 \\
Esfahan & 32.39 & 51.39 & 1585 & 1968 \\
Neistan & 32.58 & 52.47 & 1870 & 1971 \\
Varzaneh2 & 32.26 & 52.39 & 1250 & 1956 \\
Mobarakeh & 31.04 & 52.49 & 2050 & 1965 \\
Peykan & 32.13 & 52.10 & 1300 & 1965 \\
Yazd abad & 32.43 & 52.44 & 2200 & 1965 \\
Garmeh & 33.32 & 54.59 & 950 & 1966 \\
Bayazeh & 33.20 & 55.20 & 1450 & 1968 \\
Shahre babak & 30.07 & 55.09 & 1890 & 1961 \\
Raver & 31.15 & 56.33 & 1290 & 1961 \\
Boshroyeh & 33.52 & 57.25 & 885 & 1970 \\
bovanat & 30.28 & 53.4 & 1990 & 1971 \\
\hline
\end{tabular}

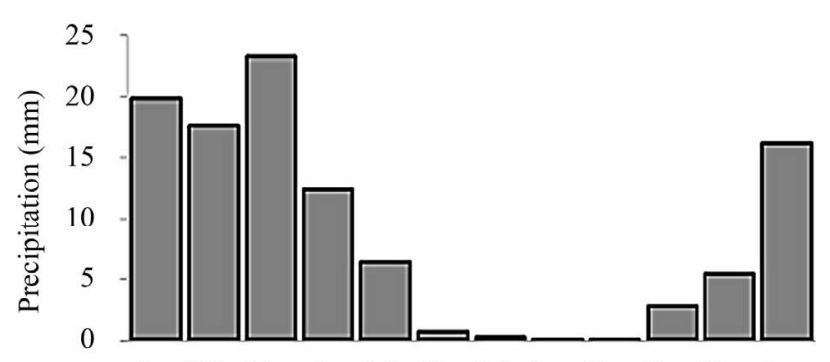

Jan. Feb. Mar. Apr. May Jun Jul. Aug. Sep. Oct. Nov. Dec. Months

Figure 1. Monthly precipitation averages in Yazd province (1973-1997). 


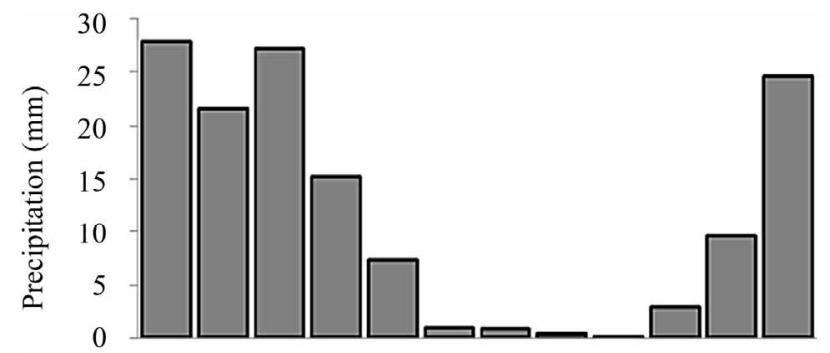

Jan. Feb. Mar. Apr. May Jun Jul. Aug. Sep. Oct. Nov. Dec.

Months

Figure 2. Monthly precipitation averages in the control region (1973-1997).

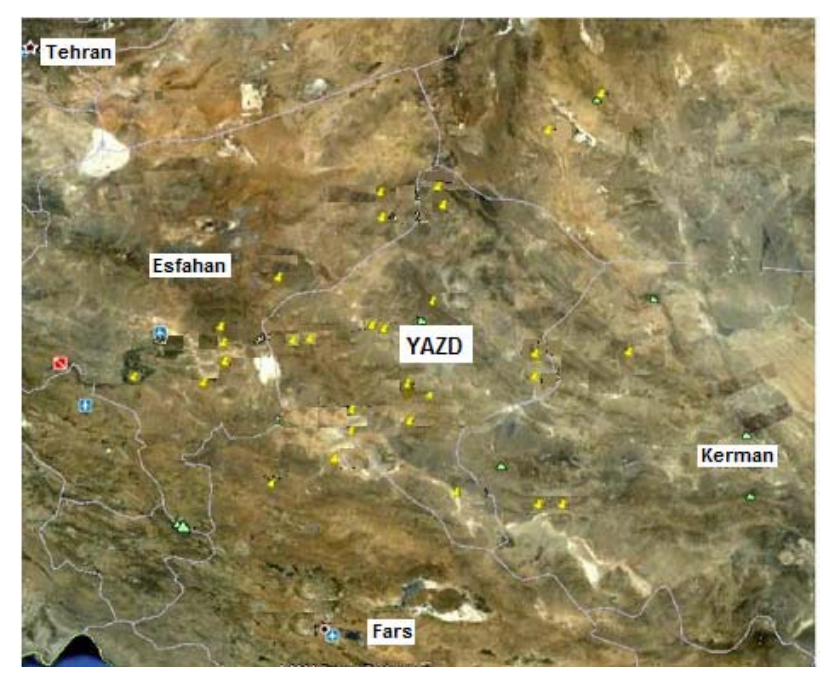

Figure 3. Position of the selected target and control stations in the study area.

\section{RESULTS}

As mentioned before, the period of implementing this could seeding project is during 30 Jan to 29 Apr 1999 over Yazd province. Thus in order to obtain a regression relation between long term average of precipitation of control and target stations, the long term precipitation averages for Feb, Mar and Apr in two target and control regions before seeding operation (1973-1997) have been calculated and used.

The Figure 4 compares the long term precipitation variations of two control and target regions in 3 aforementioned months over 1973-1997. As it is evident by the graph below we can expect to find a high correlation between these two regions regarding precipitation variations.

By using the long term average of precipitation in two target and control regions the below regression equation has been obtained:

$$
\mathrm{Y}=0.722 \mathrm{x}-0.389
$$

Figure 5 illustrates the linear correlation of precipitation for two study regions during 25 years. The correla-

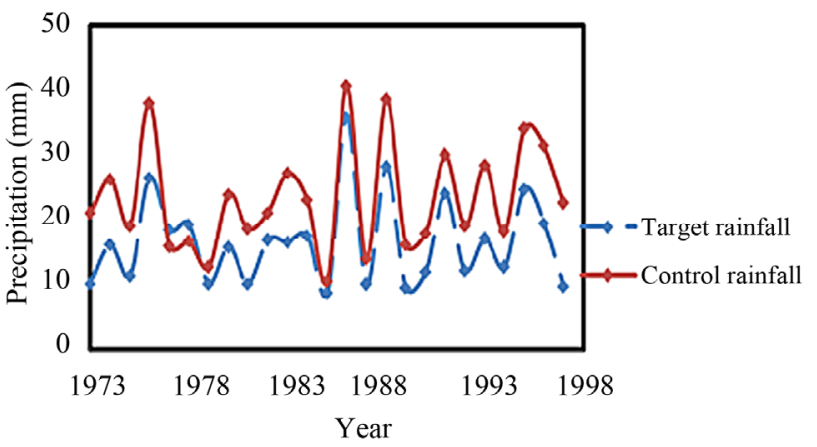

Figure 4. Yearly variations of the average precipitation of 3 months (Feb, Mar and Apr) during 1973-1997, in the target and control regions (respectively blue and red curves).

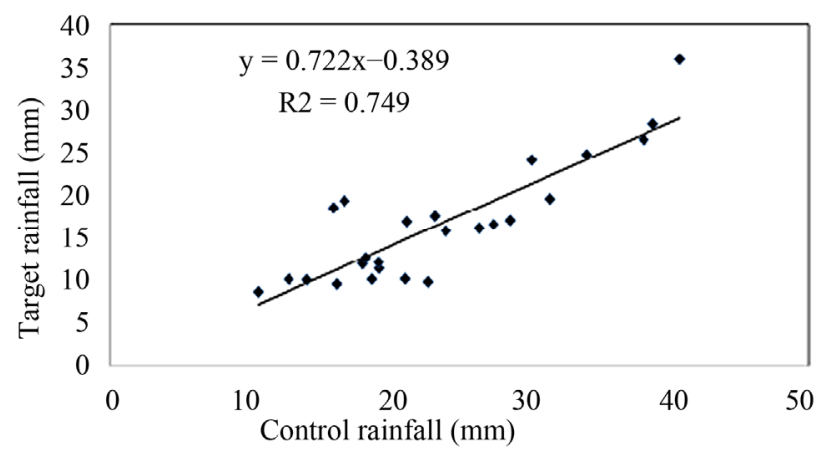

Figure 5. Linear correlation of average precipitation of 3 months (Feb, Mar and Apr) between control and target regions during 1973-1997.

tion rank is estimated about $75 \%$, which indicates the fact that the control stations appropriately have been selected.

Figure 6 shows the observed, estimated and long term average precipitations in our target region, comparing them gives interesting information about the result of seeding operation.

Through the obtained regression equation, the rainfall amount in target region over Feb-Apr 1999, has been estimated about $27.57 \mathrm{~mm}$, whiles comparing to the observed rainfall amount that was $34.23 \mathrm{~mm}$, we found an increase of rainfall around $19.46 \%$ through cloud seeding in Yazd province.

\section{CONCLUSIONS}

Cloud seeding is recounted one of operational and emergency ways to coup with drought as well as water shortage over a specific period and a given region. Implementation of cloud seeding project and increasing of rainfall amount considerably depend on cloud sort (for example the conductive clouds are suitable to be seeded) and atmospheric conditions. Yazd 1 project was a cloud seeding operation in Yazd province over February, March and April of 1999, that was operated by Iran National Center of Cloud Seeding Researches and Studies. We used 


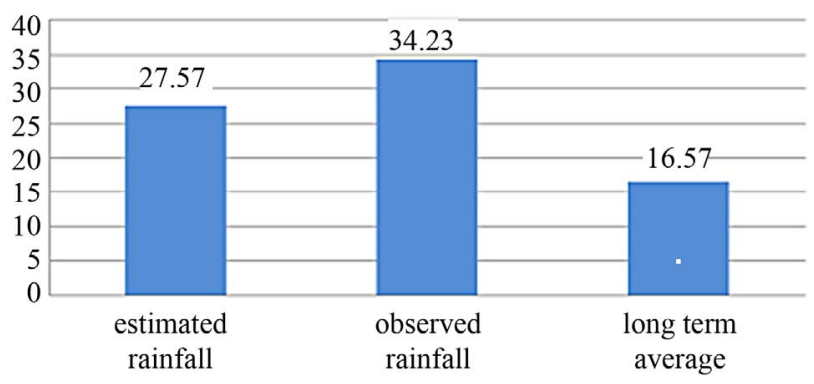

Figure 6. Long term average precipitation (1973-1997), estimated precipitation (for Feb, Mar and Apr of 1999), and observed precipitation (over Feb, Mar and Apr of 1999) in Yazd province.

the regression method for evaluating the results of this project. For this purpose the meteorology stations and the rain gages were selected from Yazd province as target region, and neighboring provinces as control regions. Through linear correlation analysis between precipitations of two target and control regions over a 25 -year period (1973-1997), we found a high compatibility for them (with a correlation rank around $75 \%$ ) that indicates a good linear relation to estimate the rainfall amount for target region over Feb, Mar and Apr of 1999, so we estimated the rainfall around $27.57 \mathrm{~mm}$. whiles, the long term rainfall average was $16.57 \mathrm{~mm}$ and observed amount was $34.23 \mathrm{~mm}$.

This evaluation implies the success of the Yazd 1 project. As comparing to the estimated rainfall, we had a considerable increase of precipitation around $19.46 \%$.

Usually cloud seeding operation is developing for different objectives regarding the target region conditions, any way in a dry-semi dry country such as Iran cloud seeding operation basically aims to water resources management in drought period and irrigating of dry farming. Thus we suggest developing such projects for other parts of the country along with pro-feasibility studies of could seeding, in order to coup with water shortage.

Although the main objections are raised against the use of the historical regression method for the evaluation of the influence efficiency. First of all, the problem of the stability of Eq.2 under conditions of microclimatic changes arises. The period of cloud seeding activities may differ, in principle, from the preceding period, in particular, due to the change in frequency of various types of synoptic situations, which can be characterized by various regression coefficients between target and control area precipitation [17]. Another probability of the origin of differences, connected with time is possibly, the difference in microclimatic trends of target and control area precipitation, however the origin of the differential trend is unlikely in the case of the near location of the target and control area [2].

\section{REFERENCES}

[1] Bruintjes, R.T. (1999) A review of cloud seeding experiments to enhance precipitation and some new prospects. Bulletin of the American Meteorological Society, 80, 805820.

doi:10.1175/1520-0477(1999)080<0805:AROCSE $>2.0 . C$ $\underline{\mathrm{O} ; 2}$

[2] Kloskove, B.P. (2010) Statistical evaluation of results of operative precipitation enhancement activities over large areas using historical regression method. Russian Meteorology and Hydrology, 35, 265-271. doi:10.3103/S1068373910040047

[3] Weather Modification Advisory Board (1978) The management of weather resources. Report to the Secretary of Commerce, 2 Volumes.

[4] National Academy of Science (1966) Weather and climate modification, problems and prospects. Vol. I. NASA/ NRC Publ.1350, Washington DC, 39 p.

[5] National Academy of Science (1966) Weather and climate modification, problems and prospects. Vol. 2. NASA/ NRC Publ. 1350, Washington DC, 210 p.

[6] (1973) Weather and climate modification, problems and prospects. NASA/NRC, Washington DC, $258 \mathrm{p}$.

[7] American Meteorological Society (1992) Planned and inadvertent weather modification. Bulletin of the American Meteorological Society, 73, 331-337.

[8] Smith, E.J., Adderly, E.E. and Walsh, D.T. (1963) Cloudseeding experiment in the snowy mountains, Australia. Journal of Applied Meteorology, 2, 324-332. doi:10.1175/1520-0450(1963)002<0324:ACSEIT>2.0.C $\underline{\mathrm{O} ; 2}$

[9] Shaw, D.E. and King, W.D. (1986) Feasibility study to assess the potential of a cloud seeding experiment over the catchment of the Snowy Mountains Scheme. SIROMATH Pty Ltd., Report.

[10] Warburton, W.J.A. and Wetzel, M.A. (1992) Field study of the potential for winter precipitation enhancement in the Australian Snowy Mountains. Atmospheric Research, 28, 327-363. doi:10.1016/0169-8095(92)90016-4

[11] Snowy Mountains Hydro Electric Authority (SMHEA) (1993) Snowy precipitation enhancement project. Draft Environmental Impact Statement.

[12] Changnon, S.A. and Lambright, W.H. (1990) Experimentation involving controversial scientific and technological issues: Weather modification as a case illustration. Bulletin of the American Meteorological Society, 71, 334-344. doi:10.1175/1520-0477(1990)071<0334:EICSAT>2.0.CO ;2

[13] Rosenfeld, D. and Nirel, R. (1996) Seeding effectiveness - The interaction of the desert dust and the southern margins of rain cloud systems in Israel. Journal of Applied Meteorology, 35, 1502-1510. doi:10.1175/1520-0450(1996)035<1502:SEIODD $>2.0 . C$ $\mathrm{O} ; 2$

[14] Nirel, R. and Rosenfeld, D. (1995) Estimation of the effect of operational seeding on rain amounts in Israel. Journal of Applied Meteorology, 34, 2220-2229. 
doi:10.1175/1520-0450(1995)034<2220:EOTEOO $>2.0 . \mathrm{C}$ O;2

[15] Iran National Research Centre of Cloud Seeding Studies (2010) Enhancement of water extraction over Gavekhoni watershed through cloud seeding operation.

[16] Khalili Sr., M., Seidhassani, M., Golkar, F. and Khatibi, V.
(2009) Results of cloud seeding operations for precipitation enhancement in Iran during 1999-2007. National Cloud Seeding Research Center, Yazd.

[17] Neyman, J. (1967) Experimentation with weather control. Journals of the Royal Statistical Society, Series A, 130, 285-326. 